\title{
An Interview with Gordon Fairweather
}

\begin{abstract}
Alex Zisman: Bill C-55 defined the new refugee determination system and led to the creation of the Immigration and Refugee Board which you are now heading. Did you make any personal contributions to this Bill?

Gordon Fairweather: I had discussions with the Minister about how best to comply with the policy of the government. I had something to say about "safe third country" in concert with other people who were advising the Minister. The Bill, as enacted, contemplates advice from me on this section.
\end{abstract}

AZ: How and when did your decide to accept the chairmanship of the IRB?

GF: I was invited to allow my name to go forward by the Deputy Clerk of the Privy Council, Jack Manion, in July of 1987. I gave them an answer shortly afterwards, because I saw in the chairmanship of the Immigration and Refugee Board a natural extension of my work as Chief Commissioner of the Canadian Human Rights Commission. Human rights and refugee determination are inexorably linked in my opinion.

AZ: One of the most controversial aspects of the new refugee determination system has been the "safe third country" provision. Why has the "safe third country" access test never been implemented?

GF: This is a matter of the policy of the Government of Canada on the recommendation of the Minister of Immigration, and I assume (I have nothing but an assumption) that the Minister was persuaded by the advice she received about "safe third country" and has not seen, in the first 11 months of the working of the new Board, any need to implement the provision.
AZ: Why do you think the government thought it imperative to include this principle in the legislation in the first place, in spite of the opposition voiced by refugee advocates?

GF: Because I believe the government was persuaded that many claimants who had access to refugee determination processes in the United States or in Western Europe would shop for a country, depending on where they would prefer to settle

\section{... if the system were to be flooded by claimants from} one of the

"safe third countries" ... the "safe third country" provision could be utilized ...

eventually. And it was to prevent "forum shopping" (and I put that phrase "forum shopping" in quotes) that I assume the "safe third country" provision was included.

AZ: What lies ahead for the "safe third country" provision?
GF: It is part of the legislation and can be invoked if circumstances dictate - for example, if the system were to be flooded by claimants from one of the "safe third countries", where claimants would have appropriate means of asserting their claim. The "safe third country" provision could be utilized if large numbers of claimants prefer Canada as a place to have their claims determined rather than making a claim in, say, the Netherlands, Belgium or the United States for that matter. At the moment no consideration is being given to invoke that section; there is no recommendation that it be utilized, either in all or in part. The section is there, but it is not now in use.

AZ: I think that the problem with implementing that clause lies in the difficulties to determine which country is actually a "safe third country" for particular claimants and under particular circumstances.

GF: That is exactly right, but that does not prevent it from being proclaimed discreetly, in the sense that a country might be safe for claimants from country $X$, but not safe for claimants from country $Y$. That's a possibility.

AZ: The initial or preliminary hearing was designed primarily to apply the credible basis test (in addition to deciding whether a claimant was eligible) and was intended to be very brief. But, on average, initial hearings have been far fro $m$ brief and quite often have rivalled full hearings in length. This may have resulted from interpreting the credible basis test as one involving the credibility of the claimant and not just whether there is credible evidence for a claim. Furthermore, so far the initial hearings 
have managed to eliminate, according to the January 1-October 31, 1989 figures, barely 5.4 per cent of all claims initiated (480 rejected claims out of 8,894 decisions rendereed). In fact, this percentage has been slowly but steadily dropping every month over the past few months. This is coupled with the fact that fewer and fewer claimants are forced to go through these hearings. Yet, initial hearings kept the cost of processing each claimant eliminated at this stage, according to some estimates, at well over $\$ 20,000$. Do the initial hearings still make any sense in light of the possible misinterpretation of cred $i$ bility, their extended length, low elimination rate and high cost per claimant eliminated?*

GF: I do indeed believe initial hearings continue to make sense. An initial hearing is a very handy, quick and expeditious way of preparing, in a sense, for the full hearing. The personal information forms, for instance, that arise at border points or inland, may need improving.

AZ: Do you envisage streamlining the preliminary hearings?

GF: We do indeed envisage streamlining initial hearings because 60 per cent of the refugee claims come from five source countries, and we would hope that that fact will be reflected in a more rapid process where manifestly founded claims could be identified and the procedure completed in much less time than it now takes.

AZ: How would this be done? Have there been any guidelines, official or unofficial to streamline claimants from any of these countries?

GF: We are working first with the Immigration Bar and with Immigration Canada to see what steps are to be taken to shorten the time a manifestly founded claim would

\footnotetext{
* The downward trend in the elimination rate at the initial hearing stage has become even more palpable since the conduction on December 10, 1989 of this interview with the IRB Chairman. The new rate for the first quarter of 1990 is 3.3 per cent. For the latest IRB statistics see Pp. 2 and 26.
}

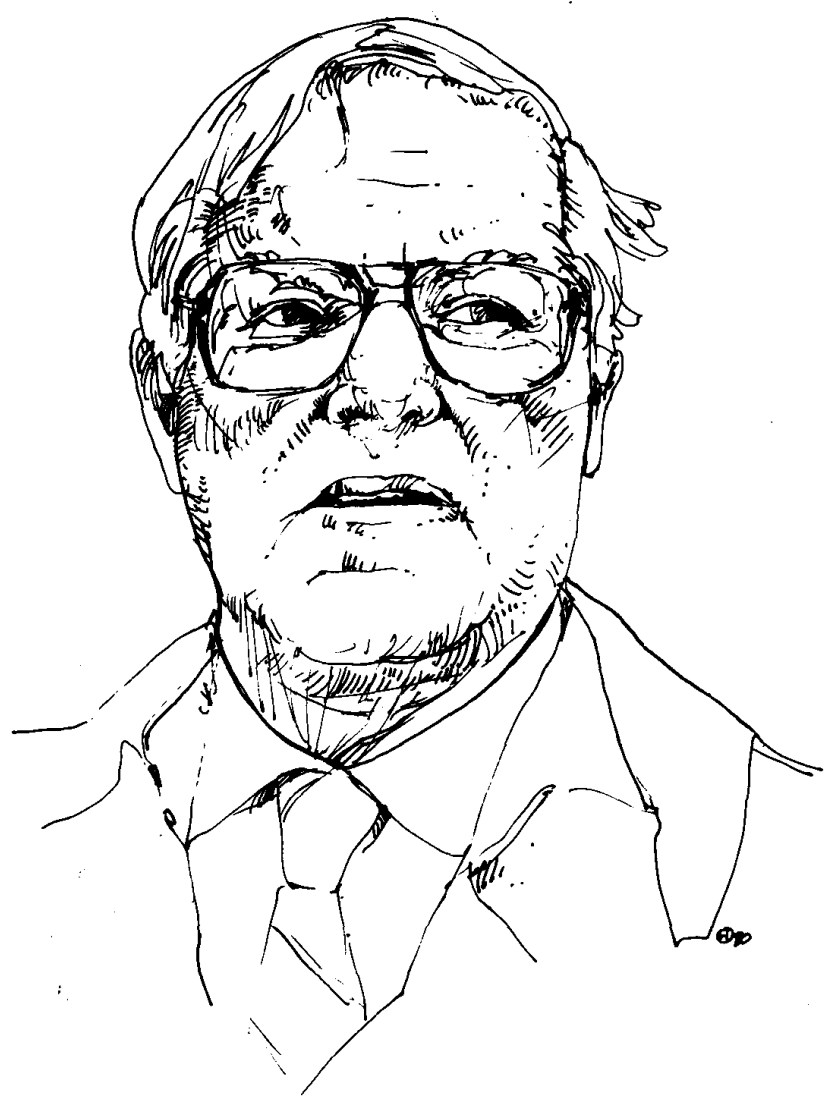

Gordon Fairweather: "There is not a more independent refugee determination system that I know of in the Western world."

require to go through the system. Now, having said that, that will put great stress on the full hearing. If the claims are manifestly founded, and move rapidly, there is only one outcome, and that is the full hearing.

AZ: So you still believe in the usefulness of the initial hearings...

GF: I don't think that eliminating them is going to do what some people think. The problem is the numbers of people who are making claims and getting to the full hearing stage. I don't mean that that is an insurmountable problem and therefore makes the act or provision any less efficacious. What it does is tell us that we need to streamline that process and make sure that there isn't an unconscionable delay in allowing or getting a claimant his or her entitlement to the full hearing, which is, after all, where the final status is deter- mined. But just eliminating the preliminary hearing would not accomplish that.

AZ: Would it not be better to use the initial hearings as a very exceptional procedure to screen only groups of refugee claimants from non-refugee producing countries, and otherwise allow people to go directly to the full hearings?

GF: I am not yet prepared to do that. I would be quite surprised if we were able to identify so readily non-refugee producing countries. It is true that 70 per cent of the claims come from five countries. Having said that, there are 30 per cent that come from other countries, not in large numbers. But if one is a refugee, a Convention Refugee from that lesser number, one would want the same entitlement as, say, those coming from the ignominy of Iran, Sri Lanka, Lebanon, China, or El Salvador for that matter. Those 
countries are the major source countries, but that doesn't mean that we forget the fewer claimants from, say. Burma. In truth, the initial hearing is part of the legislation. I am not persuaded by numbers or by policy, that it is an appropriate time to ask Parliament to open up the Immigration Act for the long debate that will ensue before change occurs. The good, if there is any good in it, is not worth the price in parliamentary time, nor in the time of the Immigration and Refuge Board to effect this change. It is not an urgent matter, yet, in my opinion I will be prepared to talk to the Parliamentary Committee when they ask the Board to appear, but I can't imagine the Government agreeing to find the parliamentary time necessary to $m$. ke this change. We live in the real world where Parliament has a host of issues before it. A very long and intensive debate has transpired over the issue of refugee determination and I don't think it is yet the time to go back to Parliament and say: "Look, how about another bit of your time to make this change." That may come, but not immediately.

AZ: I conclude, therefore, from what you say, that large numbers of claimants will be fasttracked to full hearings. There will be fewer claimants de facto having preliminary hearings, but no de jure change will take place. In reference to de jure issues, another contentious issue has been that of appeals. Why have appeals been limited only to areas of law or jurisdiction?

GF: Because this is the trend signalled by the Supreme Court and our Superior Courts that judicial deference will be given to the expertise of Boards that Parliament sets up to decide the facts. I find no mystery in this. And I am very surprised that lawyers fix on this issue. The Board was set up to try to relieve the courts in a variety of areas. The court gives deference to the Boards that Parliament has decided will be the fact finders. This is true in human rights law. It's true in labour law. It's true in rate settings for electrical energy or power, and so on. It is a natural evolution of administrative law.

AZ: As anticipated, decisions have not been immune to inconsistencies, errors in judgement and mistakes in fact. Has the IRB been able to categorize the most common errors and mistakes affecting the decisions so far? How has the IRB handled these errors and mistakes to ensure that they will not be repeated? What alternative mechanisms would you prefer to see implemented to ensure the correction or rectification of these errors or mistakes?

GF: Yes, decisions have not been

We ... do indeed
envisage
streamlining
initial hearings ...
where manifestly
founded claims
could be
identified
and the procedure
completed
in much less time ...

immune to errors in judgement and mistakes of fact. And if they are capricious, the courts will tell us so.

AZ: How many decisions have been appealed on points of law or jurisdiction? How many decisions appealed on points of law or jurisdiction have been overturned? How many decisions have been contested because of errors in judgement and mistakes in fact? How many decisions contested because of errors in judgement and mistakes in fact have been overturned by the Minister?

GF: I have brought along the latest statistics for the period from January to November. There have been 363 negative decisions at the full hearing of the Refugee Determination Division. There have been 181 applications for leave to appeal, of which 50 were granted. Seventy-five were denied and one appeal up to now has been allowed. So that must say something about, first of all, what the courts think of our ability to find facts. Also, I have to say frankly, I was very surprised that only 50 per cent of those who got a negative decision applied for leave to appeal.

AZ: Some lawyers complain that re asons are not being given for denying an appeal ...

GF: I suppose lawyers will always object when the courts make a decision against their client's interest, but I am not overly disturbed about that. The Federal Court of Canada has been very vigorous in ensuring that the former Immigration Appeal Board, and now our Immigration Appeal Division and Refugee Determination Division, live up to the expectations inherent in the legislation. It doesn't mean that every time a lawyer has a case, he or she is going to be successful.

AZ: The main concern is that when the errors in judgement and mistakes are not related to areas of law or jurisdiction, then rejected refugee claimants have no grounds to launch an appeal.

GF: Well, perhaps that is the case. That is the scheme of the legislation, and as I say, about 50 per cent of the applications for negative decisions have been before the courts, and that signals to me that in an area where 10,000 decisions have been made, not very many of them lend themselves to being overturned by the courts. We are a human institution. Errors will be made. And the scheme of the Act is to allow the Minister discretion to intervene before deportation. And she has carried out that responsibility. I am not defending the Minister. We are an independent agency. But the Act seems to me to be unfolding as the policy indicated.

AZ: So on the whole you seem satisfied with what the percentages indicate. 
GF: I am surprised at the percentages, I am not satisfied with any legislation - or the perfection of any legislation - having to do with human entitlement. We have given very extensive training to members of our Board, unheard of in Federal Boards and Commissions, and have, just in the last month, completed an intensive refresher course for every member of the Board, given by outside experts, including Professors Hathaway and Lemieux, and Professor Murray Rankin from the Faculty of Law at the University of Victoria, and by a specialist in evidence who is with the Federal Department of Justice in the Montreal district.

AZ: The Canadian Section of Amnesty International has suggested a centralized review capable of reversing a negative decision on points of law, on the facts or merits of the claim and on questions of mixed fact and law. What do you think about this proposal?

GF: There is a centralized review. A centralized review is the Minister on any deportation. But I have no comment. That would be a matter for the Government to decide. This matter was thoroughly debated, and the number of applications for leave seems to show - at least it indicates to me - that, by and large, the system has worked rather effectively. But Amnesty has been helpful, and continues to be helpful to us. We use Amnesty and York University, of course, the Centre for Refugee Studies, for our country profiles and for the evolution of international law and refugee matters. I am frankly a little bit worried. I wouldn't myself want to be in a position of being a kind of court of appeal to colleagues who have the responsibility and duty to make independent, unfettered decisions about claims based on hearings.

AZ: The hearings were designed to take place in an informal and non-adversarial setting. Yet in most hearings panel members occupy podiums. If being on a raised platform were not enough to inspire respect, other participants must also stand up whenever the members enter or leave the court room. Why did this formalization take place? What sort of impact has it had on the hearings?

GF: I think it has had a positive impact, and the informality is still the rule. There have been importunings on both sides of this issue and we try

\section{... the number of applications for leave} seems to show ... that,
by and large
the system
has worked
rather
effectively.

to balance. The Board itself is a quasijudicial kind of place. I am of the generation that is not unduly upset by standing up when somebody enters the room. What we want is the result. The non-adversarial plan is very fully in effect, and it is mostly in effect in matters of substance. This is not a casual matter, like getting a drivers license or marriage license. The members have important discretion, important decisions to make, involving the life and liberty of human beings. I think I have looked at most of the rooms. Some have the podiums, some don't, but I don't think it has had any impact on the hearings. I hope not. Why six inches would unduly affect somebody's rights is beyond me. But the main point is the non-adversarial aspect of the full hearing. That is a breakthrough. It is unheard of, it gives us very serious issues to contemplate in global law, of evidence and all these other matters. That's the change, not the trappings of a hearing.

AZ: What role do you play in the appointment of new panel members? Can you or do you actually nominate or veto any candidates?

GF: I am flattered to say that the Government consulted very widely in an unprecendented way. And I most certainly actually did nominate and did veto candidates. Veto in a sense. I can't veto. That is the prerogative of the Governor in Council. But what I did was warn the Governor in Council - or the Minister in this case, who made the nominations to the Governor in Council -. But actually we (the Board and the people who advise me) are rather proud of the openness of the Minister to hear, to accept suggestions about appointments, and not make other appointments. This is unprecedented in my experience in Ottawa.

AZ: The Refugee Board has been quite a model in terms of appointing members from ethnic communities and visible minorities. Yet, in one category it seems to be lacking. A lot of refugee claimants come from Spanish-speaking countries. Despite the fact that many Board members do speak Spanish, no members so far have come from any of those Spanish-speaking countries.

GF: I don't accept that at all. There are many people on the Board who are from the Philippines, from other parts. But we didn't go through a process of saying $X$ number of Spanish-speaking Canadians, therefore there would be a percentage or quota. We wanted to get representative candidates. And I am not going to have a discussion here on whether every group that makes up the plurality of this country is as thoroughly represented as other groups. It is a very plural Board. And I've heard from the Czech community that there is nobody from that wonderful East European country, and I've heard from the Chinese community that there are not enough Chinese. In truth, it is a national plural Board with 50 per cent of its members from identifiable ethnic groups. 
AZ: That's right. But, what I'm saying is there are close to 20 countries where Spanish is the official language. And the Philippines is not one on them. And, as far as I know, I haven't seen any Board members who come from any of those countries.

GF: I didn't expect that question, because my mind doesn't work in that way. I am a pluralist. And I wanted to have a representative Board. I didn't want to have the Board divided by percentiles of this or that or the other who make up the plurality of Canada.

AZ: How are the refugee hearing officers hired?

GF: They are hired by Public Service Commission notices like any other public servants.

AZ: The RHOs have been concen $d$ about the fact that neutral cross-examination could be ineffectual and could only contribute to uncertainty. As a result, as Sam Laredo, Elaine Pollock and Jan Marshall indicate in the December 1989 issue of Refuge, "the RHOs have been encouraged to be more persistent and probing in their questioning". Do you believe that RHOs can actually remain neutral and strictly non-adversarial if they are to be effective?

GF: I have nothing to say about this question. We spent the 9 th of December with the Immigration Bar in Toronto discussing the role of the RHO. I haven't any problem with their neutrality and being non-adversarial, but they are certainly entitled to be probative. I mean, they are not just sitting there. It is important that the Board have the facts, and the RHOs' duty is to help them ascertain the facts. But they are not to emulate some of the vigorous cross-examination that one sees on television. But Sam Laredo is in charge of this, and his comment in Refuge is the Board policy.

AZ: So you don't see any contradiction?

GF: Cross-examination has become a pejorative. The cross-examination doesn't need to be if it is pursued professionally. We are reminding RHOs of that. Otherwise, it means that Board members might get into that kind of questioning. And that is something that I personally want to avoid.

AZ: Interpreters at the IRB still remain officially untested and untrained. They have been informally hired and no specific and uniform guidelines exist to rate them. They feel sidelined within the participatory nature of the hearings. I understand that the IRB intends to introduce, in the near future, written and oral tests which will contribute to screen, hire and rate the interpreters.

GF: I agree thoroughly in the need to professionalize the profession of the interpreter. It continues to be a challenge. We ourselves have worked to achieve this. First of all, we have increased the per diems, the pay for interpreters. In some places they are more informally organized to increase their own professionalism, and so on. But the lack of formality and screening of interpreters remains a challenge for the Board. And, of course, for CEIC, who has charge of the initial hearing.

\section{... the main point is the non-adversarial aspect of the full hearing. That is a breakthrough.}

AZ: Has the IRB any plans to ensure a greater participation of interpreters in the decision-making process, particularly with regard to their specific performance at the hearings?

GF: While we would want to consult with them about their performance at the hearings, we would not, of course, involve them in the actual decision itself. We realize that the unevenness of interpreters can contribute to difficulties with the hearings and we are trying to do something about that.

AZ: You mentioned that the members are receiving what could be described as an exemplary ongoing training. Do you anticipate providing the same quality of ongoing training for the interpreters?

GF: I can't answer that today because I am not totally sure. I think that what certainly can happen is training about what is expected of them at hearings. What I am hedging about is training about their ability in that language. I presume that comes when their ability is tested in screening and hiring. But we well could be of assistance. If interpreters would like, we could offer assistance in what we expect during the hearing itself. That might be helpful. A good suggestion.

AZ: The IRB has been trying to get the latest academic research fed into the system to boost documentation resources. How successful have these efforts to engage the academic community been?

GF: They have been successful in the sense that we expect within the next six to eight weeks to be on-line. It has been a hardware problem. We've had to first of all get the Board up and running. And then get the proper computer. And we needed first of all the computers to assist our work in scheduling and all that kind of business. But I am informed that we will be on-line with a variety of sources of academic research within the next couple of months.

AZ: In any procedure, the analysis of previous cases can prove helpful. Will case studies be made available to lawyers and other interested parties in the refugee determination process?

GF: Yes, absolutely. Lawyers are entitled to know reasons, both positive and negative for refugee determination; lawyers and any other interested party. We must be accountable to both research and the profession of law.

AZ: How long does it now take to process a claimant from the time of landing to that of the full hearing? 
GF: It is different depending on where you are in the country. And that is one of the sad realities. Sixty per cent of the all the claims originated in the Toronto Regional Office. So, the length of term here is longer than it is in Vancouver, Calgary or Montreal. And I can try to give you a breakdown, I don't have in my head the actual weeks, but I think in the rest of the country it is from six to eight weeks. Here it might be three to four months, and that is very troublesome.

AZ: Have there been marked changes in this waiting period over the past eleven months?

GF: Yes. The time in Toronto has expanded. And that is unacceptable to our Board. We are trying to do something about it.

AZ: What is causing the "front-end backlog" or "frontlog"?

GF: The relentless and quite understandable pressure of numbers. In particular, the numbers of claimants in Toronto is causing this.

AZ: What is being done to reduce or eliminate this threat?

GF: We are working on a system to try and speed up the manifestly justified.

AZ: Is this just a matter of numbers, or is it also related to the types of claims? I understand that there has also been an emerging trend for persons who have been in Canada for extended periods of time suddenly applying for refugee status after facing deportation for serious criminal convictions. How much has this trend affected the refugee determination process? What do you plan to do about it?

GF: There are those kinds of things, but they wouldn't account for this very huge backlog. They would be the exception, rather than the rule. There is no doubt that those claims are coming but not to the extent of making a huge impact on numbers.

AZ: Is there a procedural way of dealing with them?

GF: There are procedural ways. First of all, I think the cooperation with the Immigration Bar is at its highest point since we began operations. However, there are still - and there are fortunately very few - lawyers, who would use a delay to benefit what they think is benefitting - a client. Now, those are rare exceptions. Constant adjournments are not a tactic used by the majority of the Bar, but where it is used, we have urged our members to be very tough, not granting adjournments. I can't embellish that answer. Adjournments that subvert through the courts of the Minister of Justice are wrong and should be discouraged.

AZ: Some of them are unavoidable, when a member is sick and cannot be substituted, for example ...

GF: A member or lawyer. But the courts of justice have been reluctant to grant adjournments. I mean, lawyers are expected to be ready to proceed. And one should expect the same deference from the Immigration Bar to this Board as one would get in the Civil Court.

AZ: Would it be fair to say that, in spite of some reservations about what have been perceived as specific legislative flaws, the implementation of Canada's new refugee determination process has generally proven successful in practice?

\section{We must be accountable to both research and the profession of law.}

GF: Well, I am embarrassed to be answering this. Some think I am too sanguine. What I am not sanguine about is where delays or where buildups mean that people have to wait too long in great anxiety about the completion of their claim. On the other hand, we have been able to make some 10,000 - just over 10,000 - decisions. Granted that some of that has been because CPOs have conceded. Those concessions may be a key to speeding up the process. What, of course, this will mean - and I have said this earlier in this interview -, is more strain on the full determination.

AZ: How do you account for this?

GF: Well I think, certainly from the point of view of the Immigration Bar, they have told us in no uncertain terms, that it is time to go on with it, get on with it. That Parliament has spoken.

We live in a country where there is respect for the rule of law. And it's diverting in energy, time and resources to try to reargue something that has now been decided.

Meanwhile, out there there are convention refugees who are entitled to the protection of Canada, and I think that our critics have seen that they remain our major objective.

That doesn't mean that the court challenge, mounted by the Canadian Council of Churches, will not give us useful guidelines when it is argued, and presumably - depending on the result - it will eventually end up in the Supreme Court of Canada.

That doesn't cause me to lie awake at night wondering what the courts will do. What it causes me is to say that the courts may indeed want to indicate this or that section, does not conform with the Charter.

If so, of course, Parliament may want to respond to that. But meanwhile the Board will go on about its duties.

Of course, I am not frightened by what the courts might do. Who could be frightened living in a country like this about what a court might say about a law that Parliament has propounded in the middle of a charter that is the supreme law of Canada?

Now, if this law exceeds the Charter, we will be told so, and we will make the necessary adjustments.

But, it won't, by any means, hobble the Board, or the Board's ability, to make a decision for a refugee claimant. 
AZ: Do you think that Canada by now has more than earned its stripes to act as a respected international consultant on adjudicating procedures?

GF: I do indeed. I have just come back from Oxford, from Ditchley Park, together with Professors Adelman and Hathaway. The group included American, British and some European refugee experts, including the United Nations High Commissioner. And the result of the conference was that the Canadian system was held up as the model that the Western world may wish to follow, based on the fact that we are independent and objective and not subject to government foreign policy in refugee determination.

AZ: Could this expertise be turned into a profitable proposition?

GF: I think that the country profiles could be used widely. I am not sure that they will be profitable in the monetary sense, but we distribute them widely. The United States immigration judges use them. They have been exported to many countries in Western Europe. France has told us that there are exceptional in their objectivity. So, if by the word profit you mean whether their objectivity is used by others, then yes, of course.

AZ: What about the other meaning of profitable?

GF: Whether Canada would sell them? I am not sure. We might contemplate a cost return, but I haven't put my head to this yet. I am so pleased that we are recognized for our objectivity, that I don't mind sharing our work at the moment. And in a way it may be the contribution Canada can make to a much larger refugee determination posture that the world would have to make.

AZ: Critics are always complaining about the costs of the IRB ...

GF: Well I have never thought that the life and liberty of a person should be evaluated in a monetary way. Yes, it is expensive. The Supreme Court of Canada, in Singh, said that administered convenience was no excuse not to give a person an oral hearing. Parliament has shown us the dimensions of the oral hearing and, yes, it will be expensive. The justice system is expensive. The medical system is expensive.

AZ: How important do you consider your personal involvement at the hearings?

\section{... the Canadian system was held up as the model that the Western world may wish}

GF: I think it is important that the Board and its Chairman participate personally in hearings. A Chairman, seems to me, must take part in the actual, substantial part of the Board's work - a hearing -, and not be some kind of remote kuba in the capital issuing directives. The year has been an extraordinary one because the work is absolutely basic to human rights; it's offering protection to children, women and men who, by a convention signed by 106 countries, are entitled to it. To be asked to do this at this stage in my life is immensely satisfying intellectually, philosophically and emotionally.

AZ: How does this compare to your role as Chief Commissioner of the Canadian Human Rights Commission?

GF: At the Human Rights Commission it was a period of honeymoon. That's a trite word to use in the sense that there were a great number of allies who looked to the Human Rights Commission to be the exemplar of human rights determinations and so on.
So, although there were some critics within society, there weren't very many. In refugee determination, it is slightly different, because there are those who have a different view of immigration, both if we were in a spectrum, you would say the right and the left, although I find the objectivity of our work immensely liberating. There isn't any ideology in the determination of a Convention refugee anymore. There are no $B$ lists. There is no automatic acceptances because of whether a state is totalitarian or authoritarian, and that is comforting to me.

AZ: You have discussed the whole development and set up of the IRB. How does it compare to what is being done in other countries? To what extent are other countries trying to imitate Canada's model?

GF: This is uncharacteristically boastful of Canada. Canada has some part of it's psyche, had to have trouble coming to terms with what we do rather well. There is not a more independent refugee determination system that I know of in the Western world. This isn't the place where the border police make determinations. It is a place where an independent Board makes the decision with the benefit of the doubt given to the claimant. That is extraordinary. At least I think it is an extraordinary and a very deeply moving experience. And the fact is that many countries welcome us, want to learn about us. We have had a stream of visitors, both senior political elected people and officials from all over the world, saying: "Show us how you've done this and is there anything we should copy." This, of course, gives me pleasure as a Canadian.

It was exciting to me that the Supreme Court relied on the Bill of Rights and the Charter to say that an earlier system for determining whether Canada is fulfilling it's obligations was not adequate. It was somebody's duty to put in place a better system. We did. But it isn't primarily the Canadian aspect. It is whether the claimant, wherever he or she may come from, has an opportunity for a fair hearing. 